\title{
HEITZER, Horstwalter, Deutscher Katholizismus und Sozialpolitik bis zum Beginn der Weimarer Republik
}

\section{Catherine Maurer}

\section{OpenEdition}

\section{Journals}

Édition électronique

URL : http://journals.openedition.org/ifha/2042

DOI : $10.4000 /$ ifha. 2042

ISSN : 2198-8943

Éditeur

IFRA - Institut franco-allemand (sciences historiques et sociales)

Référence électronique

Catherine Maurer, «HEITZER, Horstwalter, Deutscher Katholizismus und Sozialpolitik bis zum Beginn der Weimarer Republik», Revue de l'IFHA [En ligne], Date de recension, mis en ligne le 01 janvier 1994, consulté le 22 septembre 2020. URL : http://journals.openedition.org/ifha/2042 ; DOI : https://doi.org/ 10.4000/ifha.2042

Ce document a été généré automatiquement le 22 septembre 2020.

(C)IFHA 


\title{
HEITZER, Horstwalter, Deutscher Katholizismus und Sozialpolitik bis zum Beginn der Weimarer Republik
}

\author{
Catherine Maurer
}

1 Dans des genres différents, ces deux publications récentes de la maison d'édition catholique Schöningh confirment, si besoin en était, la vitalité actuelle de l'historiographie du catholicisme et des catholiques en Allemagne.

2 Le premier livre est dû à la plume de H.Hü., Professeur à l'Université catholique d'Eichstätt et spécialiste reconnu de l'histoire contemporaine du catholicisme allemand (il est notamment l'auteur d'une Kurze Geschichte des deutschen Katholizismus 1800-1960, parue en 1986). H.Hü. propose ici à un public cultivé, plus large que celui des seuls spécialistes (comme en témoigne la présence d'une précieuse annexe photographique), une véritable somme sur l'existence et le devenir des catholiques allemands au cours d'une période décisive de leur histoire. L'originalité de l'entreprise mérite d'autant plus d'être soulignée que H.Hü., loin de se contenter de l'histoire des institutions ecclésiastiques, selon une habitude bien ancrée Outre-Rhin, s'efforce de prendre en compte l'ensemble du " milieu » catholique, en accord avec le titre de l'ouvrage. Il est d'ailleurs le premier à reconnaître les difficultés d'une telle démarche, face aux faiblesses de l'historiographie allemande en matière d'Alltagsrealität des populations catholiques. Le résultat de ces préoccupations est un ouvrage qui, tout en continuant à faire la part belle aux relations Église-État (mais comment pourrait-il en être autrement, à un tel moment?), a un réel souci des caractéristiques sociales (précisées par un usage bienvenu de la statistique et de la cartographie) et des traits de mentalité (abordées de manière plus impressionniste, faute d'étude systématique dans ce domaine). Si l'analyse ne peut se départir entièrement d'une proximité évidente avec les réalités qu'elle décrit, elle n'hésite cependant pas à aborder les zones d'ombre de l'histoire du catholicisme allemand au XXe siècle, en particulier le silence presque total de l'Église sur le génocide juif. Au total, il s'agit donc d'une synthèse indispensable à toute bibliothèque d'histoire allemande. 
3 Le deuxième ouvrage n'a ni l'ampleur, ni les objectifs du premier: il s'agit en effet d'un recueil de textes. Les documents ont été choisis par Ho.H., spécialiste du catholicisme social et auteur d'une étude sur le Volksverein, parue en 1979 dans la collection de la Kommission für Zeitgeschichte de Bonn. Le recueil comporte une longue introduction aux deux grands thèmes abordés par les textes, la législation du travail (Arbeiterschutz) et les assurances sociales (Sozialversicherung); chaque document (l'ouvrage en rassemble 40 au total) est précédé d'une brève introduction. On dispose ainsi d'un instrument de travail commode sur un domaine, la politique sociale, dans lequel les catholiques allemands se sont toujours montrés très actifs. Schöningh prévoit d'ailleurs de publier dans la même collection et sur le même thème un recueil portant sur la période 1945-1963. 